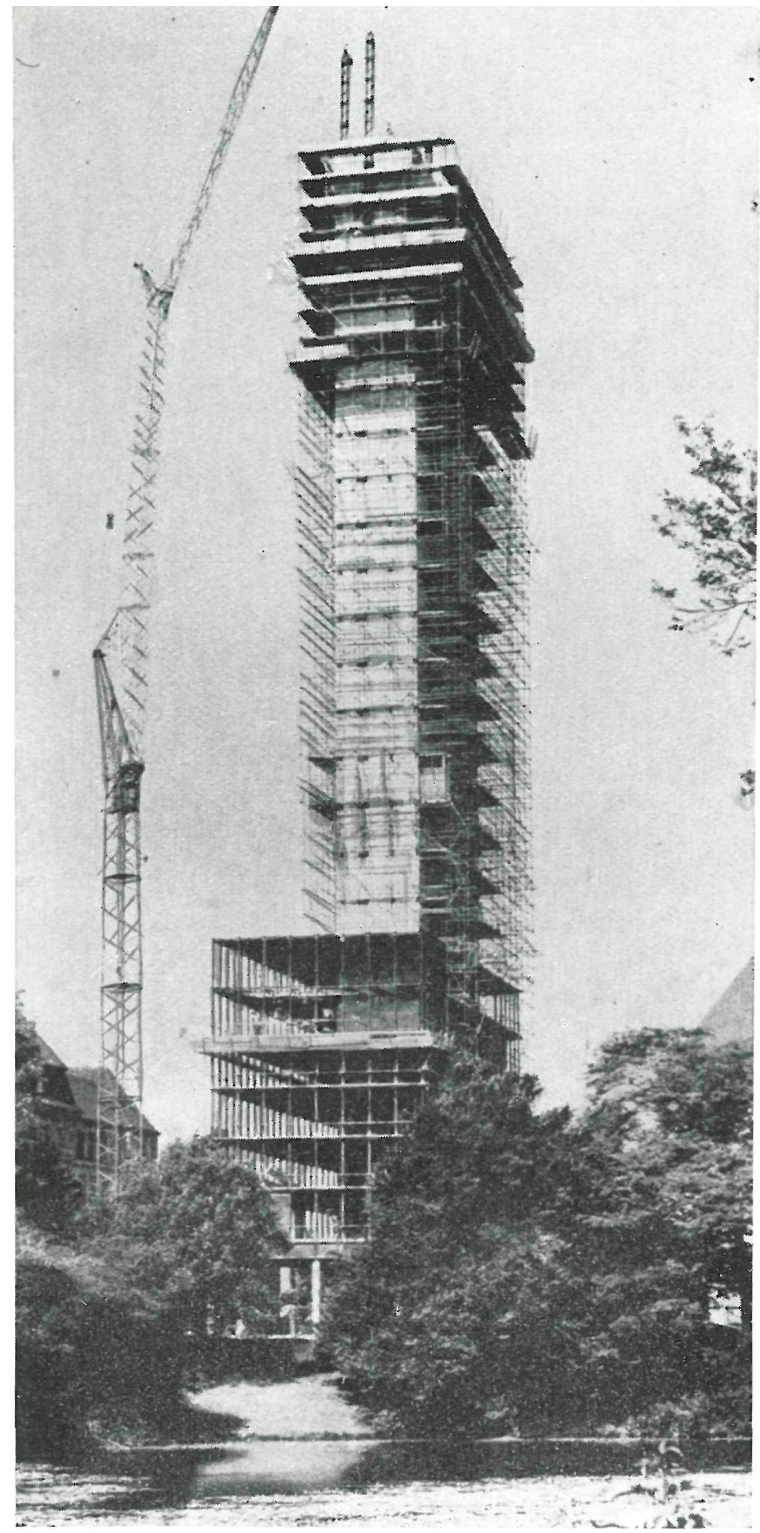

\title{
grúa para obras de gran altura
}

HOCHTIEF AG - Düsseldorf

$863 \cdot 17$

e s que $\mathrm{ma}$

En las construcciones modernas donde las estructuras se extienden predominantemente en altura, caso corriente en los llamados rascacielos, entre los elementos auxiliares de obra se encuentra, en primer lugar, la grúa.

Muchas y variadas son las soluciones que para ganar altura en las grúas se han puesto en práctica; entre ellas resalta aquella en la que la grúa, como elemento independiente, utiliza su propia pluma para elevarse a niveles superiores.

Este tipo de grúa, cuyas aplicaciones han sido múltiples, la fabrica la casa alemana Hochtief A. G.

Entre estas importantes aplicaciones se halla un rascacielos de $102 \mathrm{~m}$ de altura que recientemente se ha construído en Düsseldorf.

La grúa es de tipo de torre, pluma y aguilón. Para las alturas iniciales trabaja la grúa en forma ordinaria montada sobre su torre, la que, a su vez, se puede mover sobre las vías preparadas con esta finalidad.

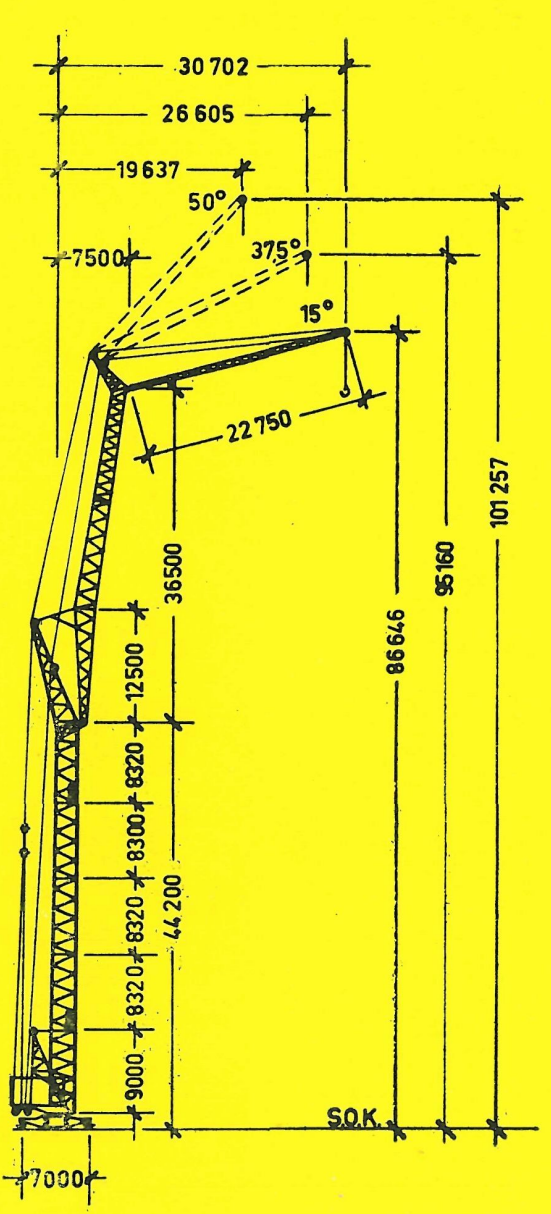



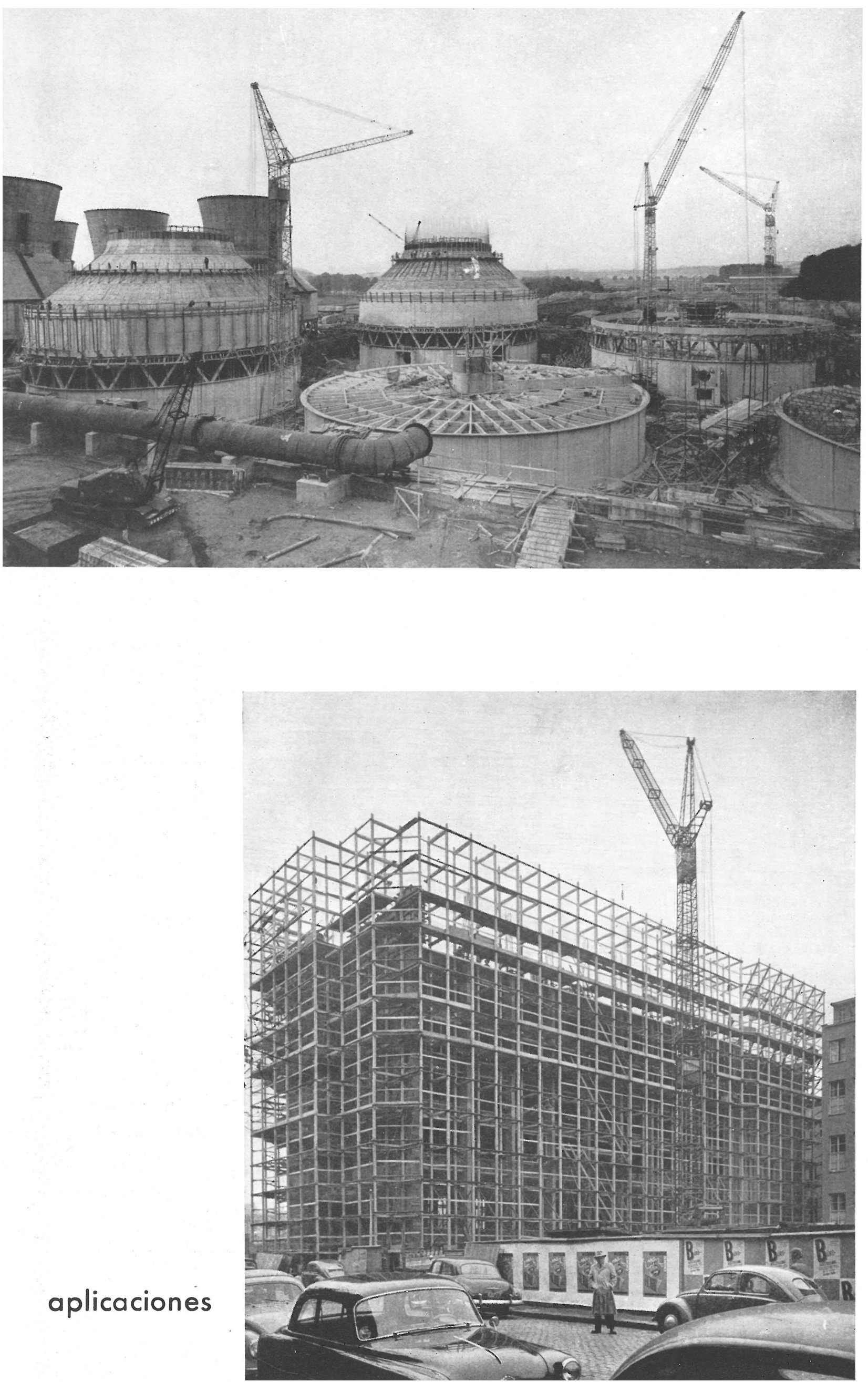


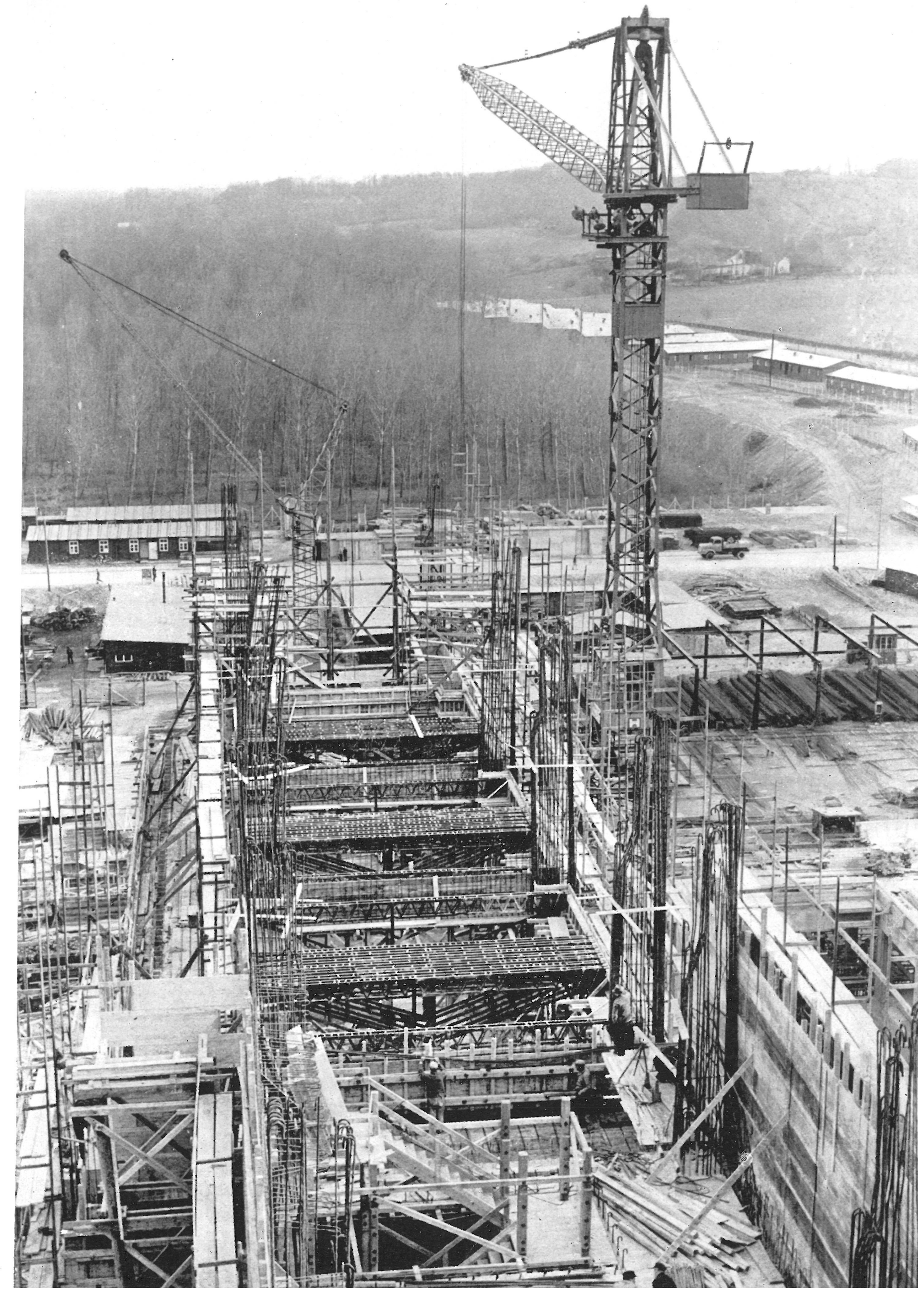




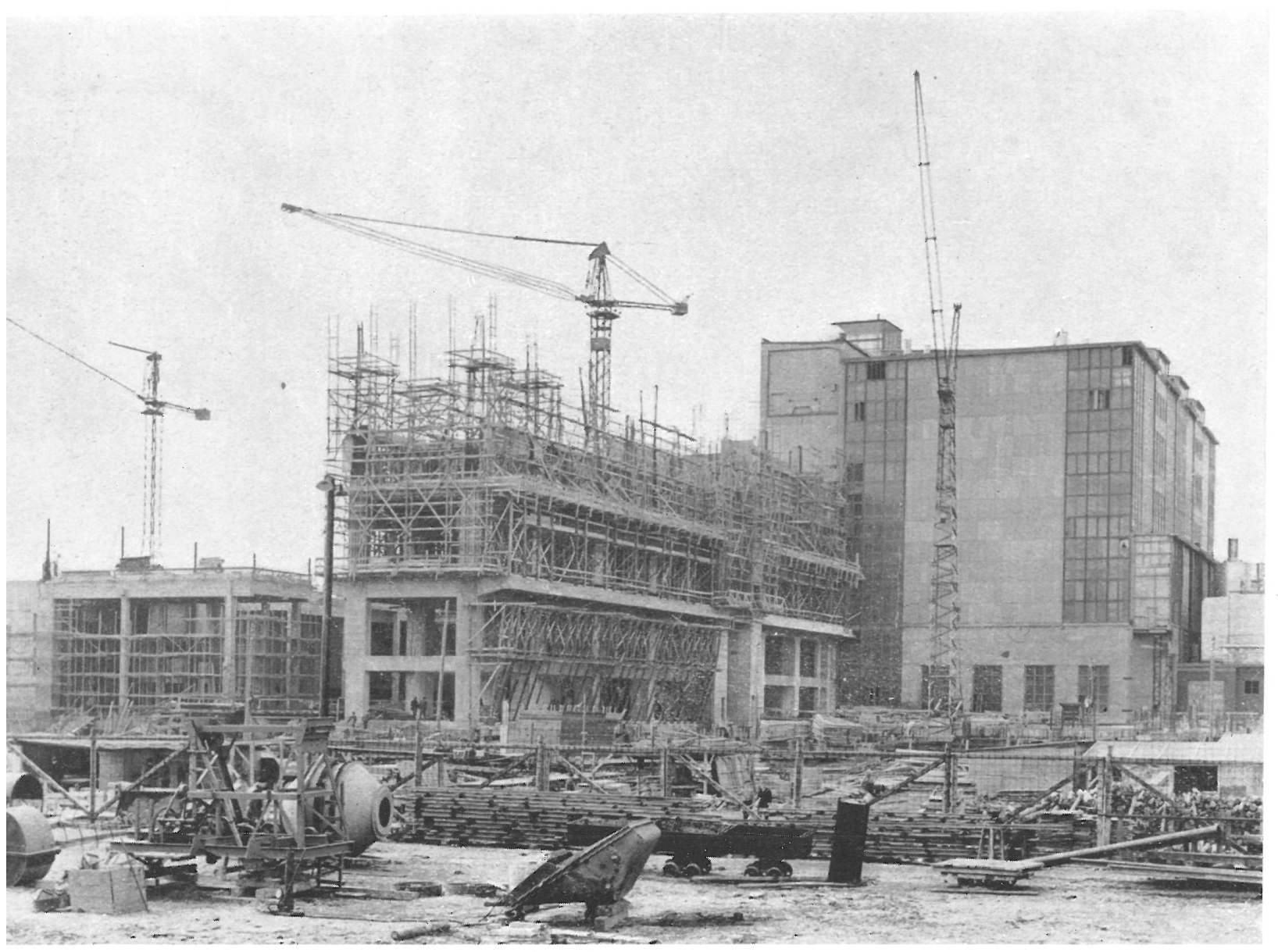

A medida que la obra se va elevando, la grúa cambia su pluma, hasta que llega un momento en que ésta queda fija y sobre ella se monta un aguilón. La primer pluma constituye una especie de contrapeso, de cuya extremidad parten los cables o vientos que se fijan en la base de la grúa. Otra pluma ligera se monta después sobre la extremidad de la pluma añadida al cuerpo, que también se utiliza como contrapeso. Las extremidades de estas plumas auxiliares llevan una polea por la que pasa el cable de fijación o contrapeso, constituyendo un conjunto de gran rigidez y altura.

Una vez añadida la gran pluma, la cabina de mandos no tiene visibilidad directa sobre el punto de descarga. Esto exige que, en este lugar, se instale un puesto de telecomandos para seguir directamente las maniobras de descarga por el operador encargado de ello.

La estabilidad de la grúa, incluso con vientos del orden de $150 \mathrm{~km}$ de velocidad, ha sido comprobada por agentes oficiales alemanes, ya que, dada la gran altura a que ha de elevar su carga, las razones de seguridad así lo exigían.

Se comprenderá que, por las grandes dimensiones de sus elementos estructurales, los transportes de la grúa de una a otra obra requieren particular atención.

La capacidad y radio de acción de la grúa constituyen dos variables cuyo juego depende de las condiciones particulares de cada caso y tipo de carga, pero que siempre se hallan dentro de las necesidades corrientes en este tipo de obras cuya altura es muy grande con respecto a su mayor dimensión en la base. 